\title{
Police Officers Do Not Need More Training; But Different Training. Policing Domestic Violence and Abuse Involving Children: A Rapid Review
}

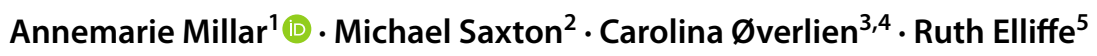

Accepted: 24 September 2021 / Published online: 7 October 2021

(c) The Author(s) 2021

\begin{abstract}
Although the police have been identified as a key service provider when responding to domestic violence and abuse (DVA), very few studies have investigated their response in relation to children. This review aims to examine children's experiences of police response in the context of DVA and to explore how the police understand and respond to children living with DVA. A rapid review of the empirical literature on the police response to DVA involving children was undertaken. PsycINFO, Web of Science and ProQuest were searched. Studies with a qualitative element, concerning children under 18 with experience of police involvement, or police experiences of children, in the context of DVA were included. The final sample comprised of six studies. Using reflexive thematic analysis, four key themes emerged in relation to children: children's experiences of DVA; fear, uncertainty, and mistrust of police; confronting "childism": a matter of children's rights; and going beyond empathy: equality and justice. Regarding the police, three key themes emerged: variability in police response; limited view of police role; lack of professional competence. The findings underscore the need for awareness raising and an urgent review of the training officers receive regarding the impact of DVA on children. They also highlight the pivotal role of police when responding to DVA where children are present, as well as to advance the frontiers of research by including not only adults and professionals but also the most vulnerable DVA victim: the child.
\end{abstract}

Keywords Children $\cdot$ Child $\cdot$ Domestic Abuse $\cdot$ Domestic Violence $\cdot$ Intimate Partner Violence $\cdot$ Family Violence $\cdot$ Police Officer · Law Enforcement Officer

\section{Overview}

This paper explores the unique complexities inherent in the police response to children experiencing DVA. In doing so, the paper provides relevant background information that is

Annemarie Millar

amillar20@qub.ac.uk

1 Research Consultant, Queen's University Belfast, 6 College Park, Belfast BT7 1PS, UK

2 Western University, 1137 Western Rd \#1158, London, ON N6G 1G7, England

3 Norwegian Center for Violence and Traumatic Stress Studies (NKVTS), Oslo, Norway

4 Department of Social Work, Stockholm University, Sweden, NKVTS, Postboks 181, 0409 Oslo, Norway

5 Teaching Fellow, School of Social Work \& Policy, Trinity College Dublin, College Green, Dublin, Ireland critical in understanding the contextual factors that relate to this issue. Attention is given to the background of this paper to sufficiently discuss the contextual factors (i.e., racism, marginalization, policing role/ militarization, police training) which are fundamental when viewing DVA as part of a wider policing context. This paper then moves to explore two research questions focused on children and police experiences in DVA incidents through a rapid review of the literature. It then presents two individual sections detailing qualitative results of a thematic analysis examining the experiences of children and police. Finally, the discussion section of this paper brings the experiences of police and children together to discuss key messages that emerge from the results as it relates to DVA. 


\section{Background}

\section{Policing and Protests: Mediating Realities of the Police Role}

The authors believe that integral to this review is a recognition of the contested context in which an analysis of policing DVA takes place. There are many ways to tell the story of 2020. One of the most shocking but not unfamiliar stories in the history of policing in the US was that of the protests against police brutality in response to the murder of George Floyd by a white law enforcement officer, Derek Chauvin that took place in Minneapolis, United States (US) in March 2020. As public citizens, due to the power of social media, these traumatic events are shaping and informing public attitudes and perceptions of police, policing and criminal justice system, in a radically new way. Similarly, national data reveals that whilst Latinx make up approximately $18 \%$ of the population in the US, they accounted for $30 \%$ of arrests and $23 \%$ of all searches (Downs, 2016). The American Medical Association, whilst acknowledging many law enforcement officers are committed to justice, recognises the verbal or physical violence between law enforcement officers and the public, in particular among Black and Brown communities, as a public health crisis (Ehrenfeld \& Harris, 2020). In the UK, racism has also been identified as a potential 'impact factor' that may increase the police use of force (College of Policing, 2020). These protests raised serious and important questions regarding policing and the professional conduct of police officers, not only in the US but also across the globe.

Poignantly, one of the recurring and contested of all questions being asked in this moment is, what are the police for and how should they be trained to discharge that professional role. Furthermore, what is possible for the future of policing and the criminal justice system? The definition of the police mission centres largely on crime control and law enforcement; yet studies reveal that police are involved in activities that for the most part are unrelated to crime and law enforcement. The data would suggest that, although much less visible than the criminal justice and law enforcement aspects of policing, the social service role has in fact become a much larger part of routine policing and police work and with the growing workload related to public protection tasks such as DVA and public safety and welfare (Rowe, 2014). However, in the UK, DVA is the least likely of all violent crime to be reported to the police (ONS, 2018). This may be due to negative previous experiences with the police, fear they will not be believed and/or supported, lack of understanding of the process or simply may not want police involvement (Her Majesty's Inspectorate of Constabulary, and Fire \& Rescue Services, 2019).

Related to these discussions is what Kraska (2007) refers to as the increasing "militarization of police":

$[\mathrm{T}]$ he real concern when discerning police militarization is one of degree - or put differently, the extent to which a civilian police body is militarized. Police militarization, in all countries, and across any time in history, must be conceived of as the degree of or the extent of militarization. Any assertion that the police are or are not militarised is simply misguided. (Kraska, 2007, p. 503)

The paramilitary aspects of policing, extend far beyond the police uniform, into the minds and bodies of new recruits during training which to date has focused more heavily on law enforcement and a "pseudo-militaristic" style of policing (Gibson, 2016, p. 2; Kraska, 2007); endorsing what authors Sloan \& Paoline calls a 'warrior mentality' (2021, p.4). This type of approach to policing is more likely to increase the brain's instinctual threat response system, or fight or flight response (Andersen, 2017, p. 7; Fridman et al., 2019): “The common denominator to every call is the individual officer, their skills, abilities and perceptions". Within this context, the 'use-of-force" defence and threat of violence by officers is often deemed reasonable and justified (Kraska, 2007, p. 503). Importantly, Kraska (2007) points out that a more paramilitary style culture is highly appealing to a certain segment of civilian police. It is clear to see that within this context, children and young people (CYP) may be less likely to receive police attention, empathy and resources at incidents of DVA.

\section{Police, Children and Racism}

Space restrictions limit discussion of children's perceptions of the role of police in society. For a thoughtful treatment of the subject, see Powell et al. (2008). However, younger children typically focus on the punitive role of the police regardless of experiences with police. A US study by Finklehor et al. (2001) exploring the attitudes of child crime victims (aged 12 and over) to police, reporting violent crime and help-seeking, found that children fear that the police will be unable to protect them from the offender, especially in the most serious kinds of abuse or fail to help them understand what happened and gather information about the crime. Only $28 \%$ of violent crime suffered by young people was reported to police compared to $48 \%$ of violent crime suffered by adults (Ibid., p. 18). Contemporary research examining the relationship between police-youth interactions found evidence of police-initiated post-traumatic stress symptomology (PI-PTSS); with black and latinx boys from lowincome neighbourhoods being over-represented in police 
stops (Gearhart et al., 2021): "Police-youths interactions rarely result in an arrest; as a result, youth can develop the belief that they are being policed for merely existing" (Ibid, p. 2). Research reveals the behaviour of officers were critical in shaping police-youth interactions; such as verbal taunts about race or sexuality, physical contact including being frisked, thrown to the ground, or slammed into a wall (Nordberg et al., 2016). It is clear from recent protests, many of them led by children and young people of all ages, joining a global movement demanding an end to all forms of police violence and racism.

These findings raise important questions about factors (racism being a primary consideration, followed by socioeconomic status) that influences CYP's perceptions of the police and critically, the likelihood of seeing, and more importantly, feeling the police as professionals who are there to help them in situations such as DVA. However, positive police interactions, both formal and informal, can significantly improve an individual's perception of the police (Nordberg et al., 2016); helping children to see beyond stereotyped perceptions and discern a more personal, human face of police officers. Police officers are a group of professionals who are involved in the lives of CYP in many different contexts; even if they are not comfortable and/or willing participants. However, they are in a unique position to make a difference in the lives of children:

The importance of the quality of police interaction with victims cannot be overstated. Good, sensitive police work can, of itself, set the child on the road to recovery, and may have a greater contribution to make to future wellbeing than therapeutic or other services. (HMIC, 2015a, p. 13).

\section{Impact of DVA on Children}

Globally, definitions of DVA have broadened to include a much wider set of actors, that now include CYP living with DVA (Øverlien \& Aas, 2016; Richardson-Foster et al., 2012; UNICEF, 2017). The child's experience of DVA goes beyond just witnessing, in that they see, hear and feel the immediate and aftermath of the trauma (Callaghan et al., 2015; Katz, 2016; Stark, 2012). CYP can become directly involved when they intervene to protect a care-giver, sometimes causing physical injury to themselves (Fantuzzo \& Fusco, 2007), or they may be the direct target of the perpetrator who involves the child in the systematic abuse of them and their non-abusing care-giver (Mullender et al., 2002).

Children may also be direct witnesses to physical and sexual violence in the home (McGee, 2000), resulting in symptoms of trauma (Birkeland et al., 2021; Pynoos \& Nader, 1988). In other domestically violent households, the child may never be directly caught up in the violence, but they are still impacted when care-giving is jeopardised by the abuser's actions (Levendosky et al., 2011), and the child must adapt to living in an environment in which their daily need for comfort and security are compromised (Stanley et al., 2011).

Much of the current literature on children's experiences of DVA pays particular attention to children's use of agency and the creative strategies children employ to keep themselves and others in the home safe (Callaghan et al., 2015; Katz, 2016; Överlien \& Hydén, 2009). Concepts such as resilience, resistance and agency feature strongly in reports of CYP's experiences of DVA in the home (Callaghan et al., 2015; Katz, 2016; Överlien \& Hydén, 2009). An individual child may develop multiple strategies that are adaptive to the violent situation and perceived threat to them and other family members (Överlien \& Hydén, 2009).

More recent work, framing children's experiences of living with DVA as coercive controlling behaviour against their mother, including psychological/emotional/verbal and financial abuse, isolation and monitoring activities, illuminates the complexity of how children experience DVA beyond the violent incident model guiding the policing and criminal justice response to DVA (Stark, 2012, p. 199; Katz, 2016), which "equates DA with discrete assaults and gauges severity by the degree of injury inflicted or threatened". This work, and expanding children's experiences of DVA more generally, has important implications within the context of this paper - creating a tension between the criminal justice system's need for evidence and the nuance and complexity of children's experiences of DVA: "Reframing domestic violence as coercive control changes everything about how law enforcement responds to partner abuse" (Stark, 2012, p. 213). Shifting the policing of DVA from a violent incident-specific model to a pattern of abusive and controlling behaviours is "far more sophisticated" in terms of the policing work (Stark, 2012 p. 215) and requires enhanced skills from officers, both professional and interpersonal skills.

The recognition of children as active agents more aligned to children's rights discourse has helped to reposition children more central in the professional response to DVA. The recognition of the child as victim in their own right within the recent UK Domestic Abuse Act 2020 raises a greater awareness of the response in other States in addressing the needs and rights of CYP in policy and practice. This shift in attention from seeing the child as part of the adult's experience to a children's rights discourse presents many challenges when moving from rhetoric to reality (Freeman, 2014). Particularly in a context, that often perceives children as too vulnerable and lacking the intellectual capacity to understand the issues inherent in 
DVA. Furthermore, many officers state that talking with children is not their role (Richardson-Foster et al., 2012).

\section{Policing DVA Where Children are Present}

There is strong agreement in the literature on the critical role that the police play as part of a wider system response to children experiencing DVA (Berkman et al., 2004; Her Majesty's Inspectorate of Constabulary, 2014; Stanley et al., 2011; Vermont Criminal Justice Training Council, 2007). In terms of policing policy and guidelines internationally, there is a greater emphasis now than in the past on reporting children's presence at a domestic violence incident, showing some progress made in this area (Överlien \& Aas, 2016; Swerin et al., 2018). Police data indicates children's presence in just under half of all DVA call-outs recorded by police (Fantuzzo \& Fusco, 2007; Gjelsvik et al., 2003; Richardson-Foster et al., 2012; Swerin et al., 2018), with close to half of all children recorded being under six years of age (Gjelsvik et al., 2003; Swerin et al., 2018). Within the early literature, the police are regularly mentioned by children when they talk about their experiences of the professional response to DVA (Buckley et al., 2007; Hogan \& O'Reilly, 2007; McGee, 2000; Mullender et al., 2002). This "key moment" when police respond offers an opportunity to "convey reassurance and authority" (Richardson-Foster et al., 2012, p. 232) to children at the scene. Whilst the evidence indicates that children, once perceived as passive bystanders to DVA, are on the contrary very much involved either directly or indirectly, research also shows that police engagement with children present at the scene remains consistently limited (Elliffe \& Holt, 2019; Finklehor \& Turner, 2015; Her Majesty's Inspectorate of Constabulary, 2015b; Överlien \& Aas, 2016; Richardson-Foster et al., 2012; Saxton et al., 2020).

There is some tension between traditional attitudes to DVA and progressive attitudes held by officers who have a clearer understanding of the complexity of DVA. Qualitative research carried out in the US by Balenovich et al. (2008) involving focus group interviews with ten domestic violence detectives, found a set of three distinct roles that officers assume. The roles, argued to be informed by individual attitudes to domestic violence, involve firstly the "strict enforcer" which maintains a strong focus on the criminal justice aspect of the role, followed by the "service officer" and is more inclined towards the social services element of the case, and lastly the "integrated investigator" who responds to an incident of DVA by simultaneously addressing the legal requirements and the social needs of victims (Balenovich et al., 2008, p. 25). It is the integrated investigator which Balenovich et al. (2008) argue to be the most effective in responding to domestic violence incidents. However, the dominant role described by officers in the study was the strict enforcer; demonstrating a need for officers to be more aware of the need to address the welfare needs of victims alongside the legal aspect in order to come to a resolution. Related to earlier discussions in this paper regarding the militarisation of policing (Kraska, 2007) have obvious implications for the police response to CYP within the context of DVA. In order to provide relevant background information to this review, the authors include details of police training and education (Table 1) for the studies included in this review, discussed in the following section.

For the authors, who have made a major contribution to this field of study, an important objective was not only to provide a formative review but to go beyond the synthesised findings and analysis to produce a meta-discussion which pauses to critically reflect on what the findings tell us about our field and where it may be heading, and what is possible for the future of this aspect of professional police practice. This review aims to explore the following questions:

1. How do children experience police and police response within the context of DVA?

2. How do police officers experience and respond to children present at DVA incidents?

The following section outlines details of police training and education across the six countries included in the review.

\section{Police Training and Education}

Training, including continued education, has been pointed out as key, if the aim is to improve the way police officers respond to domestic violence incidents (Her Majesty's Inspectorate of Constabulary, 2014, 2015a, b; RichardsonFoster et al., 2012). As noted by Russell and Sturgeon (2019), in a US context, law enforcement agencies have in recent years increased the frequency of required training of intimate partner violence (IPV), yet there is still a considerable lack in several areas. Along the same lines, Eigenberg et al. (2012) argue that although basic training has increased, US police academies still spend an excessive amount of time on physical fitness and firearms techniques rather than educating future police officers on complex social and judicial issues such as domestic violence. Hence, it continues to be an area in need of improvement. Recent scholarship analysing the structure and content of academy-based basic training in the US, argue new recruits do not seem to require more training but different training; deemphasising more 'traditional' aspects of policing operations such as weapons and defensive tactics, and develop a curriculum to focus on the skills and abilities of the individual officer (Sloan \& Paoline, 2021). 


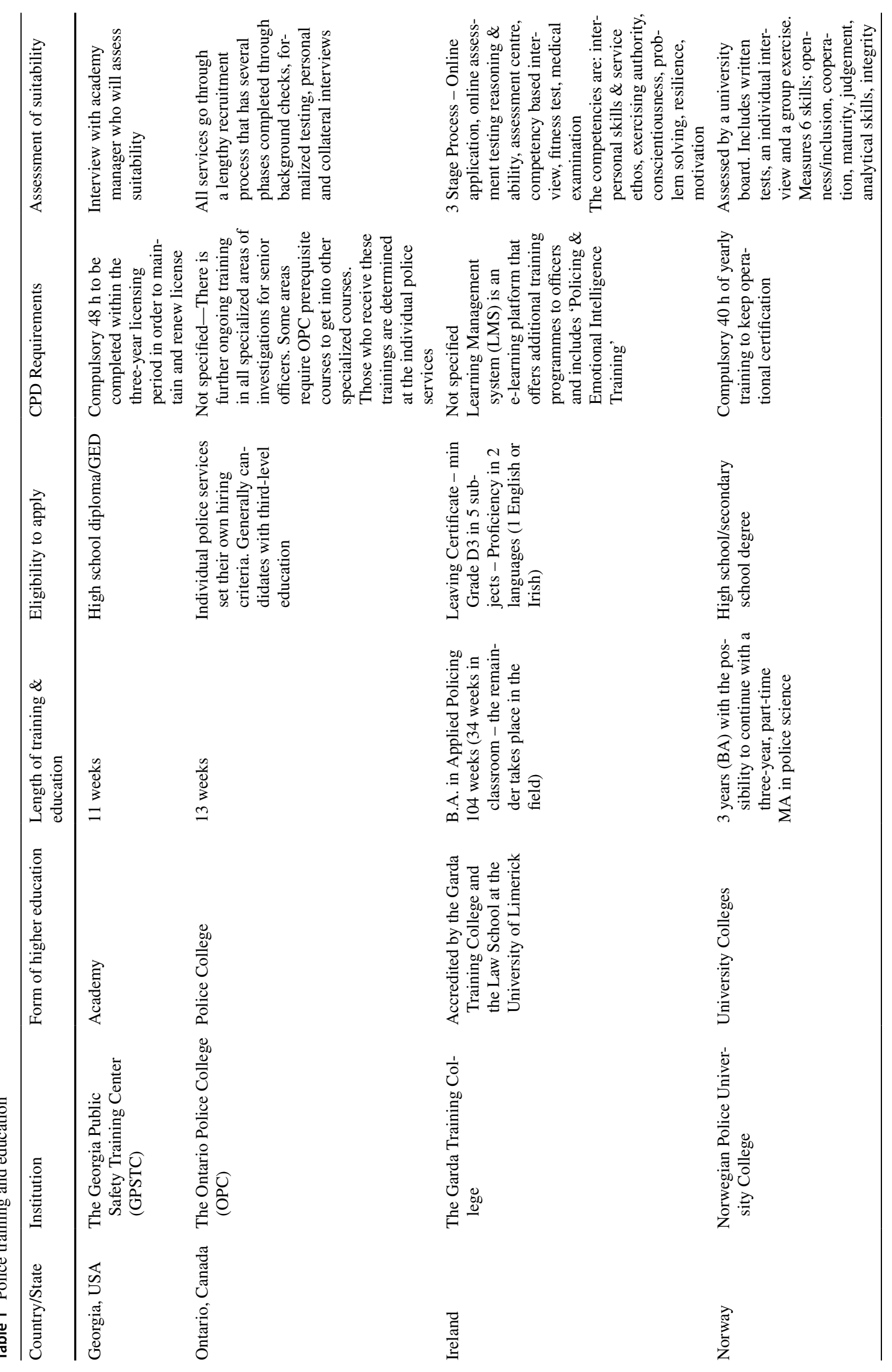




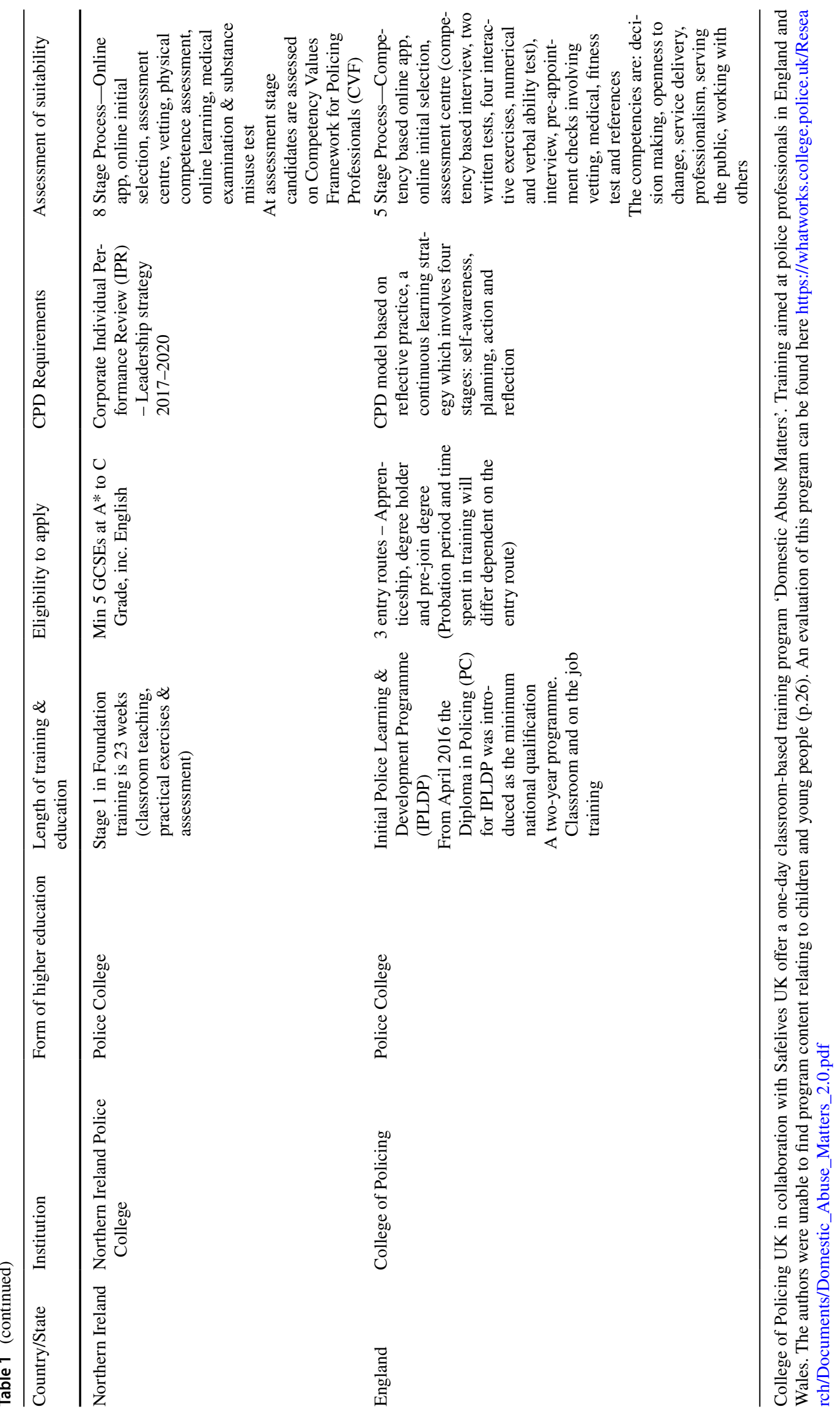


As argued by Saxton et al. (2020), when police education does include training on domestic violence, the focus is most often on adult victims, and children tend to be overlooked. Hence, the issue of limited training seems to be even more pressing in regard to children experiencing domestic violence. As suggested by Överlien and Aas (2016), this might be related to the fact that children experiencing domestic violence are too often not perceived by responding police officers as victims, but rather secondary victims or even bystanders.

Several studies identify the lack of training as one of the main reasons for police officers' reluctance to engage with (including speaking to) the children when responding to domestic violence emergencies (Överlien \& Aas, 2016; Richardson-Foster et al., 2012; Saxton et al., 2020; Stark, 2012). It is difficult to compare and contrast police officers' training between various countries, as they may vary considerably even within the same country or state/province. However, the studies included in this review are from different parts of the world, and they all show the absence of or deficiency in professional responses, including talking to the children, including them and their presence during the domestic violence incident in the police report, understanding their reactions (empathy) and collaborating with others such as child protection services.

In Table 1 (below) we have included information about the basic training for police officers in the countries or states/ provinces where the studies included in our review were conducted. The table has unquestionable gaps, as there are information and details that we did not have access to, or that were too elaborate to include. For example, we were unable to obtain detailed facts about the content of the program, such as curricula or syllabus of each course. However, it gives some important background information and context to the studies included in the review. When looking at the assessment of suitability component, which is relevant to the discussion, the data highlights some worrying disparities given the significance of the police role within the context of DVA and in general. From a historical and comparative perspective, the type of individual who may be encouraged to join the police may be those individuals who are attracted to a more militaristic/traditional style of policing and importantly reinforce children's often negative stereotypes of police (Balenovich et al., 2008; Kraska, 2007; Powell et al., 2008).

\section{Methods}

\section{Identifying Literature on Children, DVA and Policing}

A rapid review of the empirical literature regarding children and the police response to DVA was undertaken. The framework for this review was designed to enable a broad search and synthesis of the literature. This included a search of relevant electronic databases; references from included articles were checked for potentially missing studies. Three major social science and multidisciplinary databases were searched. This literature sought to identify literature, both national and international, that examines children's experiences of police response in the context of DVA or explores how the police understand and respond to children living with DVA.

\section{Search of Electronic Databases}

An initial search was conducted on three major social science and multidisciplinary electronic databases: PsycINFO, Web of Science and ProQuest. The timeframe was 2010-2019. These were accessed in October 2019. A word search for each of the key concepts related to this study was developed in order to formulate a comprehensive search statement and thereby increase the precision of the review process (Kugley et al., 2011). The complete search statement included the search terms combined below and was limited to a text search of title, abstract or subject terms to ensure comprehensiveness.

"domestic violence" OR "domestic abuse" OR "intimate partner violence" OR "family violence"

AND child* OR (child* and youth)

AND polic* OR "law enforcement"

\section{Screening and Selection of Studies}

Using the search terms described above, the initial literature search produced 2525 articles (PsycINFO: 925; Web of Science: 1224; ProQuest: 376). Article titles were independently screened by first (AM) and second author (MS) for relevance based on the inclusion and exclusion criteria (see below), with the most relevant articles retained for abstract review. For first author (AM), this process reduced the number of articles to 34 . These articles were transferred to a web-based reference management software system (RefWorks). A further 24 articles were excluded on the basis of irrelevance/duplication following a second round of observations. The full text of each of the remaining 10 articles was obtained, read carefully and assessed against the inclusion and exclusion criteria for this study. After reading the full text of the remaining 10 articles, a further two articles were excluded, resulting in a final sample of eight articles submitted for review by all four authors (AM, MS, CO \& $\mathrm{RE}$ ). Differences were resolved via discussion between all four authors based on the inclusion criteria. The details of the final six articles are summarised in Table 2. The reference lists of these six articles were then checked for relevant 
Table 2 Studies included in the review

\begin{tabular}{lllllll}
\hline Study & Year & Country & Children (n) & Age & $\begin{array}{l}\text { Police } \\
\text { Officers } \\
(\mathrm{n})\end{array}$ & Sample population \\
\hline Saxton et al. & 2020 & Canada & NA & NA & 15 & police officers \\
Elliffe \& Holt & 2019 & Ireland & 9 & $7-9$ & 14 & police officers \& children \\
& & & & $(\mathrm{n}=8)$ & & \\
& & & & 21 & $(\mathrm{n}=1)$ & \\
Rodriguez et al & 2018 & USA & 8 & $11-20$ & NA & children \& young people \\
Millar et al. & 2018 & UK & NA & NA & NA & narrative review \\
Överlien \& Aas & 2016 & Norway & 25 & $8-20$ & 24 & police officers \& children \\
Richardson-Foster et al & 2012 & UK & 19 & $10-19$ & 33 & police officers \& children \\
\hline
\end{tabular}

literature that was missed or eligible studies that may have been erroneously excluded during the screening process. No further articles were identified.

For the second author (MS), this process reduced the number of articles to 19. A further four articles were excluded on the basis of irrelevance/duplication following a second round of observations. The full text of each of the remaining 15 articles were obtained and assessed against the inclusion and exclusion criteria for this study. A final sample of 14 articles were submitted along with the first author's selections for review by all four authors (AM, MS, CO \& $\mathrm{RE}$ ). Differences were resolved via discussion between all four authors.

\section{Inclusion and Exclusion Criteria}

Once relevant abstracts/papers were identified, each was assessed for its relevance to the objectives of this research and if appropriate, selected for inclusion in this review. A study was included if it concerned children under the age of 18 with experience of police involvement in the context of DVA or police experiences of children in the context of DVA, or if it involved direct assessment of children in the context of DVA. Although there were few studies in this area, this study was focused on research that involved a qualitative element (e.g. qualitative research or a mixed-methods approach), given the focus on children's voices and lived experience of DVA. Consequently, studies were excluded if they did not have a qualitative aspect within their methods. A study was also excluded if it did not involve children under the age of 18, did not involve DVA or policing and was not written in the English language.

\section{Description of Studies}

Two of the six studies were carried out in the UK; the remaining four studies were conducted in Canada, United
States, Republic of Ireland and Norway (see Table 2). The majority of child participants were aged between 7 and 20 years old. It is well known in the field, it can be extremely challenging to recruit informants (Överlien \& Holt, 2018). Three of the six studies examined the experiences of both children and police in the context of DVA, while one focused solely on young people's experience (Rodriguez et al., 2018) and solely on the experiences of police officers (Saxton et al., 2020).

\section{Data Synthesis and Analysis}

Data synthesis and analysis was conducted by the first (AM) and second author (MS). The first author (AM) synthesised, analysed the data with children, and second author (MS), the data with police officers with a detailed discussion with the two other authors ( $\mathrm{CO} \& \mathrm{RE}$ ) upon completion. It was felt this was an effective approach to the data, rather than seeking a consensus on meaning, given the authors knowledge and experience in this field. Reflexive thematic analysis (Braun \& Clarke, 2019) was applied to data analysis. In this approach,

Themes are analytic outputs developed through and from the creative labour of our coding. They reflect considerable analytic "work" and are actively created by the researcher at the intersection of data, analytic process and subjectivity. Themes do not passively emerge from either data or coding; they are not "in" the data, waiting to be identified and retrieved by the researcher. Themes are creative and interpretative stories about the data, produced at the intersection of the researcher's theoretical assumptions, their analytic resources and skill, and the data themselves. (Braun \& Clarke, 2019, p. 594)

Given the relatively small number of studies, data was entered into an Excel spreadsheet recording themes and verbatim quotes representing each theme and general notes/ comments by the authors. Initial thematic codes were 
presented to the remaining authors and discussed for relevance and accuracy. After these discussions, the first two authors (AM, MS) continued with the thematic analysis process within the corresponding foci described above. The first step of the process involved carefully reading and rereading each article, then performing line-by-line "complete coding" (Braun \& Clarke, 2013, p. 206). The codes were assembled to find similarities and differences. The similarities were then grouped into themes and interpreted into synthesised findings based on meaning and significance. As the process of analysis was not linear, and quite often involved iterative movement by the researcher between the various phases of TA: coding, theme development and refinement, which remained closely aligned with the language of the participants.

\section{Findings with Children}

The following section discusses the findings from the six studies in this review (Table 2) exploring children's lived experiences of the police response to DVA incidents. Using reflexive thematic analysis (Braun \& Clarke, 2019) four key themes emerged: children's experiences of DVA; children's fear, uncertainty and concern and mistrust of police and police response; confronting "childism": a matter of children's rights; and going beyond empathy: equality and justice. Each theme is explored in turn below.

\section{Children's Experiences of Domestic Abuse}

Four of the six studies outlined traumatic incidents and provided evidence of the significant and prolonged suffering that children experience within the context of DVA, such that the violence and abuse become an everyday part of the child's life and throughout childhood (Elliffe \& Holt, 2019; Överlien \& Aas, 2016). A leading study by RichardsonFoster et al. (2012) employed a mixed-method approach to explore the police response to children. Their findings were based on quantitative file data from police reports of DVA across two sites in northern and southern England, supplemented with 33 in-depth qualitative interviews with officers. The file data consisted of 251 incidents of DVA during January 2007, involving 460 children or young people under the age of 18. Twenty-nine percent of children were under the age of two and $44 \%$ were under the age of five. Almost half (45\%) of the children in this study witnessed the incident, and in 53\% of cases, the abuse was rated as medium/high. Children were directly involved in a number of incidents, in which they were described as being physically and verbally abused, threatened, intimidated and dragged (Richardson-Foster et al., 2012). In one incident, for example, an 11-year-old girl had witnessed the physical and verbal abuse of her mother and she had been dragged downstairs during the incident (Richardson-Foster et al., 2012). Some children described incidents in which they felt their lives, or the life of their mother were at risk (Elliffe \& Holt, 2019; Överlien \& Aas, 2016; Richardson-Foster et al., 2012).

In Norway, Alexander, a 12-year-old boy, recalled:

I managed to get hold of the phone, then I managed to call the police right away...I was really scared and said that he had tried to strangle me and then they came... They came within 15 minutes.

\section{Children's Fear, Uncertainty and Mistrust of Police and Police Response}

When discussing the police response to such traumatic incidents, children involved in these studies often reported negative experiences with the police and expressed a great deal of fear, intimidation and uncertainty and concern about what they expected from the police (Elliffe \& Holt, 2019; Överlien \& Aas, 2016; Rodriguez et al., 2018). Concerningly, all studies found that police were seldom reported by children as a welcome intervention for incidents of DVA and in some instances, caused further distress and harm. Employing an innovative story-telling methodology (Elliffe \& Holt, 2019) when asked to describe what characters in a story might do when they see or hear the police car arrive, four young children said they would hide from the police "underneath the covers of the bed" or hide under the bed (Ibid, p. 595). Through an attachment lens (Bowlby, 1969), hiding can be seen as an adaptive, self-protecting response to danger or a threat (seeing or hearing the police car arrive) in their environment. Given that, in these traumatic moments, children may be unable to seek parental protection, police officers may be the only other option for children to seek emotional safety, reassurance and protection. Such responses may demonstrate children's stereotyped responses to be scared of the police. Interestingly, one child who received a positive police response stated "the police are the best to call" (Överlien \& Aas, 2016, p. 439). Furthermore, the studies highlighted here found that children talked about police being a frequent presence in their lives because of living with DVA in the home. Each of these incidents offer a "key moment" (Richardson-Foster et al., 2012) for police officers to restore a sense of safety but also challenge children's stereotyped perception of police: "Children's first encounter with police officers can leave a lasting effect on how they view the police and engage with them as adults" (All Party Parliamentary Group for Children, 2014, p. 2).

A study in the US exploring the experiences of eight Latino youth reported all being scared to call the police. Anti-immigrant policy in the US had significantly restricted 
their daily lives and ability to contact the police for assistance, if violence were to happen in the home (Rodriguez et al., 2018). What is clear from these accounts is the historical 'over-policing' (Ehrenfeld \& Harris, 2020) of minority/ marginalized populations in the US that are affecting [the bodies] of a new generation of children and young people:

It [House Bill 87] affected my life in a way where I can't go outside without worrying that I'll get stopped by a cop. (Joseph, age 17)

[T] hey [the police] scare me; I don't want to get deported. (Claudia, age 11)

Once again, the theme of 'hiding' in order to avoid police attention, placing them at greater risk due to increased violence in the home, demonstrates violence and abuse against children as a structural problem:

Yes, [violence would increase] because the abuser might take advantage of the victim knowing they won't call the police because deportation might happen [...]. (Amalia)

In a study conducted by Överlien \& Aas (2016) in Norway, children viewed police intervention as "serious". However, a large majority of children across studies described feeling "uncertainty and concern" about what they expected from the police, so much so that it can be a barrier for some children and young people from calling the police for assistance regarding DVA, as the quote from Simon, below shows (Overlien \& Aas, 2016, p. 437). Some children expressed concern that police often fail to protect them and their family and do not appear to care what happens to them when they (police) leave the home, placing them at further risk, as highlighted by Simon:

It would be kind of weird to call the police. "Hi, I live on X Street and my father is beating up my mother right now". That would be weird ... they would come, and then Mom would have taken Dad back. And I would have gotten beaten up. He has threatened us so many times. If anyone ever called the police, he would kill us. He would put duct tape on our mouths and lots of those kinds of things. (Simon, age 13)

Maybe they [police] didn't really do anything about it [parents fighting] . . . I don't think anybody got in trouble and it kept on going on and on. (Fiona, age 9; as quoted in XX, p. 597)

[T] hey [police] just aren't gonna care. (Jorge, age 15; as quoted in Rodriguez et al., 2018, p. 593)

\section{Confronting "Childism": A Matter of Children's Rights}

What is clear from children's reports is the lack of direct contact and meaningful communication between children and officers and the sense that they were not taken seriously and treated differently to adults within this context. Children's experiences and needs are rarely a consideration, unless they have been physically harmed/hurt or are witnesses as part of any subsequent investigation (Elliffe \& Holt, 2019; Överlien \& Aas, 2016; Richardson-Foster et al., 2012). In three of the studies reported here, children had made the emergency call to the police. Richardson-Foster and colleagues found that in 11 incidents (4.4\%) children made the call to the police (Richardson-Foster et al., 2012).

Despite evidence of the significant emotional and psychological harm caused by DVA for children, it continues to be framed by officers as an "adult" issue. This can expose children to life-threatening situations. Frequently, children experience age-related discrimination, "childism" (Freeman, 2014, p. 5) in the context of DVA. In children's reports they recognise that their status as children is somehow less than that of adults and that the "main remedy is to grow up" (Freeman, 2014, p. 265). Children represent a challenge for officers at DVA incidents both professionally and emotionally. On a professional level, children, unless physically harmed or are witness to the violence and abuse, do not form part of any initial investigation. Some officers have a narrow interpretation of their job role and understanding of DVA, which centres on a physical incident model; therefore, children are perceived as outside the abuse (Balenovich et al., 2008; Katz, 2016; Stark, 2012).

Emotionally, children are often seen as "too vulnerable" and lacking in the cognitive and emotional capacity to discuss the abuse in the home; officers (many with good intentions) may fear opening 'Pandora's box' and may wish to avoid placing an additional emotional burden on children (Överlien \& Aas, 2016; Richardson-Foster et al., 2012). Children are human rights holders and human rights claimants under the United Nations Convention on the Rights of the Child (UNCRC). Article 12 of the UNCRC (1989), rarely cited in its entirety (Lundy, 2007), makes clear that children "are not just recognised as able to but also as entitled to be engaged [...] in the process of the construction of meaning in their own lives" (Lundy \& McEvoy, 2012, p. 129). The rights of all children to be heard and taken seriously constitutes one of the fundamental principles of the convention:

1. States Parties shall assure to the child who is capable of forming his or her own views the right to express those views freely in all matters affecting the child, the views 
of the child being given due weight in accordance with the age and maturity of the child. (UNCRC, 1989, Article 12)

2. For this purpose, the child shall in particular be provided the opportunity to be heard in any judicial and administrative proceedings affecting the child, the views of the child being given due weight in accordance with the age and maturity of the child.

The issues facing children today are complex, such as DVA and cannot be satisfactorily investigated without children. These quotes are a reminder of the importance of seeing the issue of DVA through the eyes of children and in terms of children's rights:

$[\mathrm{O}]$ ne of them goes upstairs to talk to the kids and find out what they heard. They don't do that like but they should. (Tremayne, Young Person's Focus Group, quoted in Richardson-Foster et al., 2012, p. 226)

Mary: [T]hey [police] wouldn't say "who called?" or anything.

When asked how she felt about having to answer the door to the police, she replied:

I thought I was bigger . . I thought I was a woman.

(Elliffe \& Holt, 2019, p. 597)

\section{Going Beyond Empathy: Equality and Justice}

What is most evident from children's accounts of the police response is the lack of awareness and empathy of the impact of DVA, at the time of the incidents and longer term. As highlighted in this review, children are not passive witnesses to DVA in the home; their involvement is intimate and dynamic. However, children are often left feeling dismissed, isolated and alone: "Endeavouring to make sense of complicated and frightening realities is obviously much more difficult in the absence of information" (Mullender et al., 2002, p. 96):

[They came to my house] many times. [. . .] They took mom and brought her to a cell to sleep it off, and I slept without my mother. She was gone, [. . . I I slept in my room, my stepfather was at home, sleeping. They came, got mom and left. (Ronny, age 20; as quoted in Överlien \& Aas, 2016; p. 438)

[A]nd then when he's let out, still you know, keep the kids in a safe place because the problem really, they don't, they don't help the kids and they say right, here he is, he's back out, that's it, what's the kids going to go to again? (Rachel, Young People's Focus Group 3, as quoted in Richardson-Foster et al., 2012, p. 226)

A key issue to understanding children's experiences of DVA was the response time it takes for police to attend the home when an incident had been reported (Överlien \& Aas, 2016; Richardson-Foster et al., 2012). During the time it takes for police to arrive at the home, everything at home may appear to have calmed down and if no one at the scene wishes to file a report, the offices may leave without taking further action. The possibility that police would take no further action, and leave without speaking with children present, who perhaps had made the emergency call in the first instance, is a significant barrier to children taking the serious and emotional decision to contact the police for help:

If I called the police, and if they came, everything would have been calm. Because it takes time before they arrive, and each fight does not last long. So maybe they will be late, and then mom will find out I was the one to call the police. Then Jonny [Sissel's mother's boyfriend] will be pissed and he will take that out on my mother or me. I wouldn't know if that would happen. (Sissel, age 16; as quoted in Överlien \& Aas, 2016; p. 439)

When they come straight away, they should like take him away straight away, instead of waiting around and everything and listening to sides first...they should be taken away because a mum or child wouldn't call 999 just to get a dad taken away for no reason (Louis, Young People's Focus Group 5; as quoted in Richardson-Foster et al., 2012, p. 227)

Response times were not only important from an investigative perspective; they signalled to children that police care about this matter and care about them and their families' safety:

[They should] get there in 15 minutes because when I had that [incident of DVA], they took like three hours.

(Edward, Young People's Focus Group, 4; as quoted in Richardson-Foster et al., 2012, p. 227)

For a small number of children, responding to incidents in a timely and empathetic way, listening to them and validating their experiences, and asking what they needed was associated with a positive police response: 'She was really helpful, she spoke to me rather than just my mum, she was the one that gave us the number for the NSPCC. She was just good at listening to us and that' (Nicola, Young People's Focus Group 1; as quoted in Richardson-Foster et al., 2012, p. 227).

The experiences of children highlight the significance and loss of the human/relational element regarding the police response. Empathy is a decisive quality for officers: "Empathy is particularly important, especially if we are to engage and involve some of the most vulnerable individuals we encounter who may not be able to fully express or articulate their thoughts and feelings" (College of Policing, 2016, p. 7). In addition, children have a right to equality and 
justice (UNCRC, 1989, Articles 2, 12, 13\& 19) that take into account their age, differing needs, contexts, ethnic background and religious beliefs etc. as highlighted by all the studies reviewed here. Professionals such as police officers must reformulate ideas about a legal system that is primarily designed for adults and whose rules and conventions children may not understand. This must include reformulating ideas about communication and language used in interactions with children to ensure they are treated equally and to avoid further traumatisation. As Nicola, Tremayne, Mary and Ronny themselves stated, children are entitled to learn about their rights and to have access to child-appropriate remedies when their human rights, in this case breach of Article 19, are breeched:

States Parties shall take all appropriate legislative, administrative, social and educational measures to protect the child from all forms of physical or mental violence, injury or abuse, neglect or negligent treatment, maltreatment or exploitation, including sexual abuse, while in the care of parent(s), legal guardian(s) or any other person who has the care of the child.

The following section discusses the findings with police.

\section{Findings with Police}

Five of the six identified research papers specifically discussed the police response to children exposed to domestic violence. These papers also acknowledged that policing domestic violence is complex, stressful, and often unpredictable. These complexities influence the overall police response to domestic violence in a multitude of ways and have clear implications on how police address children who experience DVA. When evaluating the identified studies, several themes emerged in regard to the police response to children. Broadly themes fell within three areas: a) variability in police response, $b$ ) limited view of police role, and c) lack of professional competence. What follows is a description of these three major themes and their related subthemes.

\section{Variability in Police Response}

Throughout the five papers there is evidence related to how police are responding to children in domestic violence incidents. One clear theme to emerge was the existence of variability in individual police officer responses to children. Part of this variability appeared to be related to differentiations in police perceptions toward children as direct victims in domestic violence situations. For instance, Richardson-Foster et al. (2012) found police officers differ in when they view children as victims (i.e., exposed indirectly, direct witness, experienced physical violence) which plays a fundamental role in the police response. Similarly, Elliffe and Holt (2019) highlighted that unless children are direct victims of physical violence, discretion is left to the individual police officer to address children. Unfortunately, what appears to be a factor across studies in whether police officers consistently respond to children is if they are direct victims of violence. This was highlighted by one one officer in Richardson-Foster et al. (2012) who was quoted as: "certainly as a first response officer I wouldn't be looking to take a statement from the child. That certainly would be somebody with a bit more sort of more skills" (p. 229). Consequently, variability in police discretions to respond to children leads to widespread inconsistencies. Indeed, police officer inconsistency was one major theme emphasized in Saxton el al's. (2020) study and underscored by the finding of outright police inaction toward addressing children in the study conducted by Överlien \& Aas (2016). These findings are supported by the accounts by CYP.

\section{Limited View of Police Role}

One dominant theme found across papers are issues related to the police role and the perceived role limitations. The findings suggest that police officers appear to take a rigid stance toward their role as law enforcement, and thereby perceive the need to respond to children as falling outside of their job role, unless directly involved in a crime. Across papers there were noted findings that officers voiced concerns about addressing the needs of children as something that is not in their role, outside their role, or another variation of being beyond the call of a police officer. In Elliffe and Holt's (2019) police interviews maintained a clear standpoint as law enforcement which can be a single focus, this is best illustrated by one officer in their study stating:

I know it sounds very cold but when we arrive we've a job to do... You have your Garda hat on, you know this is what I have to do, find out what's going on and the children are irrelevant really unless they have been assaulted. (as quoted in Elliffe \& Holt, 2019, p. 595).

This standpoint was also illustrated in Richardson-Foster et al. and's (2012, p. 230) interviews where police officers contended that their role was strictly to enforce the law and venturing outside of this is difficult to comprehend or carry out: '[W]e just take the person away that needs taking away, and we probably don't really spend much time [...].'

The narrowing of focus and the rigid stance toward the role of law enforcement was also discussed in several papers as causing tension for police officers. Elliffe and Holt (2019) found officers are increasingly being called on to move away from a narrow interpretation of the police role, one focused on the criminal aspect and investigation, to take on more of social service role (Gearhart et al., 2021). For many police 
officers incorporating a more holistic approach to address needs of families experiencing DVA outside of legalistic needs comes with a lot of discomfort. This point was echoed in Saxton et al.'s (2020) police interviews which found police officers being comfortable within their role to ensure the immediate safety of children but expressed discomfort moving beyond this immediate role. Överlien and Aas (2016) discussed this as conflict between support function on the one hand and policing function on the other. This conflict appears to lead to role confusion and ambiguity for officers who are balancing being an enforcer of law (i.e., holding perpetrators accountable) while also keeping victims safe and addressing the needs of children. However, this balance appears to be out of kilter given the evolving demands of police officers around the world, and particularly when responding to children. Elliffe and Holt (2019) underscored that traditional police models focus on identifying an injured party to determine the response are insufficient when balancing their role to include recognizing children as victims and responding accordingly. Significantly, all papers emphasized the critical need to expand the police role to further incorporate the competencies that address the needs of children, including their emotional wellbeing. Indeed, one officer quote from Överlien and Aas (2016) made the above point very clearly by stating: 'I think the victim has a right to be heard - then I think it would be dereliction of duty not to talk to the child' (as quoted in Överlien and Aas, 2016, p. 441).

\section{Lack of Professional Competence}

Across the five studies a clear theme was found related to police competencies. More specifically, police officers acknowledging the value of understanding the impact on childhood exposure to DVA and skills related to addressing children. However, interviews in several studies demonstrated a lack of awareness toward the impact of DVA on children and the continued misconception that DVA is largely an adult issue. In fact, Elliffe and Holt (2019) illustrated police officers believing the myth that children are "used to it" and "immune" to violence. Saxton et al. (2020) connected a lack of knowledge and skills directly to officer inconsistency in addressing children. Överlien and Aas (2016) highlighted that at the very least police should develop the awareness and competency to refer to appropriate resources as well as have clear understanding toward what they are expected and obligated to do. These findings demonstrate the absence of empathy for children's experience of DVA.

Officers need to realize that kids are at risk first of all. I think that they are probably getting educated that there are a lot of harmful effects of witnessing DV ... But I think the challenges are getting officers to understand that. (As quoted in Saxton et al., 2020, page 4)

Overall a lack of professional competence toward addressing children was indicated as a critical factor in the reluctance toward engaging with children. Police officers in Richardson-Foster et al.'s (2012) study expressed a lack of confidence in talking to children, concerns about distressing children by engaging with them, and not having resources to offer children. These authors equated this reluctance with fears of opening a "Pandora's box" by overwhelming the children they encounter. This fear was also highlighted in Millar et al.'s (2018) narrative evaluation, in which officers expressed concern about the potential additional emotional burden they may place on children by addressing their experience of violence. There was also this discomfort and fear of putting children in difficult positions (i.e., loyalty conflict) heard in the police interviews completed by Överlien and Aas (2016). Overcoming discomfort, fears, and reluctance was a clear barrier toward engaging with children, which is an uncomfortable prospect for many police officers, a finding in Saxton et al. (2020). This fear was also clearly highlighted in Överlien and Aas (2016) study with one officer being quoted stating: 'what strikes me is that we often seem so damn scared to talk to children' (as quoted Överlien and Aas, 2016, p. 443). Findings from these papers point to a recognition that officers do not appear to have the competence and skills necessary in responding to the emotional and psychological distress of children.

The need to develop interpersonal competencies toward responding to children was a clear theme across papers. Frequently, police officers across papers identified how a lack of training has led to gaps in officer awareness and skills to address children who experience DVA. The perennial debate surrounding the police role has important implications for the type of training officers receive. A more criminal justice, militaristic approach to training may serve to reflect or reinforce a stereotypical perception of the role of the police and service delivery and serve to attract a certain type of person to join the police (Kraska, 2007).

In Millar et al.'s (2018) review, a clear lack of developing professional skill and personal qualities, including emotional intelligence, appeared to be central in hindering the police response to children. The five studies also underscored the important difference between investigative actions and simply showing support to children. Elliffe and Holt (2019) reinforced that police engagement of children during times of crisis can be a key moment in providing safety and support. Överlien and Aas (2016) succinctly stressed that while police do not need to take the role of social workers, they do need the knowledge and skills necessary to be sensitive 
to the issues involved and the complexities that arise for children experiencing DVA.

Findings reported here indicated many police officers lacked the skills, confidence, and information required to engage with children at DVA incidents. Many officers interviewed reported feeling unprepared to respond to children. Saxton et al. (2020), for example, found training as a key factor in developing comfort for officers to engage with children. Improving the type of training officers receive was also underscored in Millar et al.'s (2018) review, which explained that a lack of training often could result in officers feeling unprepared to respond in DVA incidents involving children. This point is further emphasized by police themselves. Saxton et al. (2020) found that the majority of the police officers recognized that training increased competencies and would likely be an essential factor in reducing officer inconsistency in addressing children exposed to domestic violence.

We have a little bit of training, but I think we need more guidance, more training to help us interview children and, you know, forensic interviewing of children, trauma-based, trauma-informed training where children are involved. (As quoted in Saxton et al., 2020, page 4).

\section{Discussion}

From the findings with both children and police officers, the authors wish to discuss three key messages for developing professional police practice: Raising awareness of the impact of DVA on CYP; training to embed an approach predicated on Children's Rights (UNCRC, 1989); a focus on the skills of the individual officer to reflect the social/welfare orientation of the police role (Millar et al., 2018; Andersen, 2017). The discussion concludes with implications for research and practice.

\section{Key Message One: Raising awareness of the impact of DVA on CYP}

During the last 20 years, research on children growing up with violence and abuse in their homes has grown substantially. We now have a solid research base demonstrating a spectrum of grave negative consequences, both short- and long-term, regardless of whether the child witnesses or experiences the violence or is a direct victim him/herself. Hence, there should be no doubt that children experiencing DVA should be considered victims along the same line as adults. Furthermore, we know from research that the responses of professionals, such as police are of central importance to victims of violence and abuse (Her Majesty's Inspectorate of Constabulary, 2014, 2015a, b). Whether or not a victim is met with respect, empathy and a willingness to take the perspective of the other, is of importance for healing and for the chances the victim will reach out for help again. A child who, during a domestic violence incident, calls the police, or runs to the neighbour to ask them to call, may not do this a second time, if not met and acknowledged by the police patrol that arrives to their house, especially for children of colour. For a professional to respond to a victim in an appropriate way, where they acknowledge, listen, and act, requires skills and competence (Andersen, 2017; Millar et al., 2018); to be discussed in 'Key Message Three'.

\section{Key Message Two: Training to embed Children's Right's (UNCRC, 1989) within the context of DVA}

'Childism' (Freeman, 2014, p. 5) was a strong theme to emerge from the findings with CYP. CYP recognised that police officers often treated them differently to adults involved in DVA. This often caused further distress to CYP at an already traumatic time. Even in countries such as Norway (where the rights of children are observed more strongly) compared to Ireland, Canada, UK and USA (the only country yet to ratify the UNCRC (1989); there is an urgent need to embed training with officers that recognises children's rights within the context of DVA (KIDSRIGHTS, 2021). For example, the right to have their views taken seriously and respected (Article 12); and to seek, receive and impart information (Article 13); to be protected from violence, abuse and neglect (Article 19) and to be treated in a fair manner without discrimination (Article 2). Importantly, the reports of CYP recognised their agency and capacity within the context of DVA; any support provided must also seek to recognise and understand CYP's agency and capacity, whilst recognising the critical role the police hold in respect to CYP: "In the child protection environment, the child actor is not a 'problem'; instead, they are a survivor, and potential contributor toward solutions. However, children (bestowed with rights) cannot always access services without the assistance or involvement of adults" (Dillon, 2021, p.2). Moreover, akin to adults; children are entitled to child-appropriate and accessible remedies for breaches of their human rights-as cited above (Article 2, 12, 13 \& 19). What would this look like in practice and how could children contribute to developing it.

As 'duty bearers', police officers have an obligation to uphold these principles. However, as the findings in this study show, this is not currently common practice. There is a recognition that despite progress regarding children's independent position in society as 'rights holders' rather than as 'passive and dependent on the private family' (Tisdall \& Punch, 2012, p.3), there is a significant gap between a legal commitment to the principles of the UNCRC and what actually happens in practice. Recognising and addressing 
children as independent victims of DVA and 'rights holders' and adopting a Children's Rights-Based Approach (CRBA) have the potential to produce better outcomes and make a significant difference in terms of protecting and supporting children in this context. Each interaction between children and police officer's is a critical opportunity to disrupt negative perceptions and fear of police (Powell et al., 2008) and "[R]ebuild trust that has been lost in so many communities [...]" (Sloan \& Paoline, 2021, p.28).

\section{Key Message Three: A Focus on the skills and abilities of individual officers}

Policing is one of the most arduous occupations in the public sector; training is not just a matter of technical skills. We find it troubling that training, from our mapping of police training in each respective country (Table 1), is short, often outside academia, and seems to a large extent to focus on practical skills such as handling of firearms. This appears to be reflective of a more traditional and militaristic approach to policing (Balenovich et al., 2008; Gibson, 2016; Kraska, 2007; Sloan \& Paoline, 2021) which has little or no benefit for those citizens they are tasked to serve and protect, especially CYP within the context of DVA and beyond.

The issue of professionals with little or no training, handling demanding situations involving strong emotions and traumatized persons with complex needs, is not unique to police officers. Andersson and Överlien (2018) show how staff working at secure units for adolescents, often have to handle difficult situations involving violence and abuse, without having the appropriate training or supervision. Their main task is to support children and adolescents with complex needs, placed in care against their will, to navigate and function in their everyday life. At the same time, staff working at secure units for adolescents have often no or little training after secondary school, are low paid, and work in a low status job. Along the same lines, Walker et al. (2017) have investigated the impact on prison staff, often also with limited education and supervision, to working and witnessing self-harm among inmates who are often struggling mentally. The fact that in our societies, it is some of the least educated workers, with lowest pay and status, receiving the least supervision and continuous education, handling and supporting children and adults with the most complex needs, often after years of trauma, is a true paradox.

Authors recommend an urgent review of police training that focuses on non-technical skills that contribute to the variability in police response to children and apply findings from contemporary affective science (Fridman et al., 2019); that is very different to traditional policing methods of the past. Recent research demonstrates that an officer's interpersonal skills, emotional intelligence (EI) (Goleman, 1996) and empathy, can make a difference in an officer's ability to recognize the emotional and psychological harm caused by DVA on CYP and respond in ways that children found most helpful (Inzunza, 2015; Millar et al., 2018; Saxton et al., 2020). The studies reviewed here, found officers expressed discomfort and fear when engaging with children. Training must also take into account advancements in neurobiology and psychophysiology that play such a major role in professional decision-making and outcomes, especially for families and children of colour (Andersen, 2017, p.7): [P]hysiological arousal has the power to impact decision making and behaviour. The appropriate level of arousal can save lives [...], whereas maladaptive levels may negatively impact the way in which the event unfolds". Furthermore, developments in contemporary affective science have significant potential to inform officer training and improve outcomes for police officers and children at critical incidents such as DVA (Fridman et al., 2019). Finally, police officers may view engaging with children within the context of DVA as a complicated process, involving specialist skills akin to social workers (Laming, 2003). However, children's testimonies reveal how officers can improve their response by implementing relatively informal but effective measures that help them feel both recognised as victims rather than passive witnesses and respected as individuals in their own right.

\section{Implications for research and practice}

Taking into consideration the related ethical and methodological challenges that exist when seeking to elicit the views of child victim/survivors (Elliffe et al., 2020; Øverlien \& Holt 2018), researchers should continue to find ways for children's' voice to be heard in a way that is meaningful to policy and practice development (Lundy, 2007). A narrative of 'expertise' appears to exist when it comes to speaking with children on sensitive topics. Police can draw a boundary between their role and that of the social worker as child expert (Richardson-Foster et al., 2012; Overlien \& Aas, 2016). However, what is being asked of police is not to carry out a full assessment or provide a therapeutic intervention to children and families, but to merely "offer reassurance and information and to acknowledge children's involvement in the experience of domestic violence" (Richardson-Foster et al., 2012, p. 232). Changing the narrative of expertise may help to support police in feeling more confident in applying soft skills to the work with children in this context (Millar et al., 2018). 


\section{Conclusions}

The significant role police have in addressing children in DVA is a complex and evolving issue. While it is clear there are many contributing factors in the effective response to children in DVA incidents, as highlighted in this paper, it remains critical to continue to develop police practices and training. The question that should guide this development is what is possible for the future of the criminal justice system and policing? A major challenge to addressing any of the issues discussed in this review is the willingness by police to move beyond an approach premised on defensive tactics and authority and embrace a morerelational and human criminal justice system for all. It may sound daunting; but to the many officers, and future of children and young people, it matters.

Open Access This article is licensed under a Creative Commons Attribution 4.0 International License, which permits use, sharing, adaptation, distribution and reproduction in any medium or format, as long as you give appropriate credit to the original author(s) and the source, provide a link to the Creative Commons licence, and indicate if changes were made. The images or other third party material in this article are included in the article's Creative Commons licence, unless indicated otherwise in a credit line to the material. If material is not included in the article's Creative Commons licence and your intended use is not permitted by statutory regulation or exceeds the permitted use, you will need to obtain permission directly from the copyright holder. To view a copy of this licence, visit http://creativecommons.org/licenses/by/4.0/.

\section{References}

All Party Parliamentary Group for Children. (2014). "It's all about trust": Building good relationships between children and the police. Report of the inquiry held by the All Party Parliamentary Group for Children 2013-2014. https://www.basw.co.uk/system/ files/resources/basw_20117-10_0.pdf

Andersen, J. (2017). The science behind de-escalation and use of force decision making: Policy recommendations for police training (pp. 1-36). University of Toronto.

Andersson, P., \& Överlien, C. (2018). 'If you take it personally you break' Neglected voices on violence in secure units for adolescentssw. Social Work and Social Sciences Review, 19(3), 61-80. https://doi.org/10.1921/swssr.v19i3.1191.

Balenovich, J., Grossi, E., \& Hughes, T. (2008). Toward a balanced approach: Defining police roles in responding to domestic violence. American Journal of Criminal Justice, 33, 19-31.

Berkman, M., Casey, R., Berkowitz, S., \& Marans, S. (2004). Police in the lives of children exposed to domestic violence: Collaborative approaches to intervention. In P. Jaffe, L. Baker, \& A. Cunningham (Eds.), Protecting children from domestic violence: Strategies for community intervention (pp. 153-170). Guilford Press.

Birkeland, M. S., Skar, A. M. S., \& Jensen, T. K. (2021). Do different traumatic events invoke different kinds of post-traumatic stress symptoms? European Journal of Psychotraumatology, 12:sup1, https://doi.org/10.1080/20008198.2020.1866399

Bowlby, J. (1969). Attachment and loss, volume 1: Attachment. Harmondsworth: Penguin Books Ltd.
Braun, V., \& Clarke, V. (2013). Successful qualitative research: A practical guide for beginners. SAGE Publications Ltd.

Braun, V., \& Clarke, V. (2019). Reflecting on reflexive thematic analysis. Qualitative Research in Sport, Exercise and Health, 11(4), 589-597. https://doi.org/10.1080/2159676X.2019.1628806

Buckley, H., Whelan, S., \& Holt, S. (2007). Listen to me! Children's experiences of domestic violence. Child Abuse Review, 16, 296-310.

Callaghan, J. E. M., Alexander, J. H., Sixsmith, J., \& Fellin, L. C. (2015). Beyond "witnessing": Children's experiences of coercive control in domestic violence and abuse. Journal of Interpersonal Violence. [Online] https://www.ncbi.nlm.nih.gov/ pubmed/26663742

College of Policing. (2020). Conflict Management Skills. College of Policing Limited. https://www.college.police.uk/guidance/ conflict-management/conflict-management-skills. Accessed July 2021.

College of Policing. (2016). Competency and values framework for policing Overview of framework. College of Policing Limited.

Dillon, J. (2021). 'Wishes and Feelings': Misunderstandings and missed opportunities for participation in child protection proceedings'. Child \& Family Social Work, 1-13

Downs, K. (2016, July 14). Why aren't more people talking about Latinos killed by police? PBS News Hour. http:// www.pbs.org/newshour/rundown/black-men-werent-unarm ed-people-killed-police-last-week

Ehrenfeld, J. M., \& Harris, P. A. (2020). Police brutality must stop. American Medical Association. https://www.ama-assn.org/ about/leadership/police-brutality-must-stop

Eigenberg, H. M., Kappler, V. E., \& McGuffee, D. (2012). Confronting the complexities of domestic violence: A social prescription for rethinking police training. Journal of Police Crisis Negociations, 12(2), 122-145.

Elliffe, R., \& Holt, S. (2019). Reconceptualising the child victim in the police response to domestic abuse. Journal of Family Violence, 34, 589-600.

Eliffe, R., Holt, S., \& Øverlien, C. (2020). Hiding and being hidden: The marginalisation of children's participation in research and practice responses to domestic violence and abuse. Social Work and Social Sciences Review, 22(1), 6-25.

Fantuzzo, J., \& Fusco, R. (2007). Children's direct exposure to types of domestic violence crimes: A population investigation. Journal of Family Violence, 22(7), 543-552.

Finklehor, D., \& Turner, H. (2015). A national profile of children exposed to family violence: Police response, family response, \& individual impact. Rockville, MD: National Criminal Justice Reference Service. Available at: https://www.ncjrs.gov/ pdffiles 1/nij/grants/248577.pdf [Accessed 13 December 2018]

Finklehor, D., Wolak, J., \& Berliner, L. (2001). Police reporting and professional help seeking for child crime victims: A review. Child Maltreatment, 6(1), 17-30.

Fogarty, L. A., Curbow, B. A., Wingard, J. R., McDonnell, K., \& Somerfield, M. R. (1999). Can 40 seconds of compassion reduce patient anxiety? Journal of Clinical Oncology, 17(1), 371-379.

Freeman, M. (2014). The Future of Children's Rights, edited by Michael Freeman, BRILL, 2014. ProQuest Ebook Central, https:// ebookcentral.proquest.com/lib/ed/detail.action?docID=1901130

Fridman, J., Feldman Barrett, L., Wormwood, J. B., \& Quigley, K. S. (2019). Applying the theory of constructed emotion to police decision making. Frontiers in Psychology. https://doi.org/10.3389/ fpsyg.2019.01946

Gearhart, M. D., Bender, A., Berg, K. A., \& Jones, C. (2021). Youth profiles of police-initiated post-traumatic stress symptomology. Child and Adolescent Social Work Journal. https://doi.org/10. 1007/s10560-021-00741-4 
Gibson, A. (2016). Police College review. Police Service of Northern Ireland.

Gjelsvik, A., Verhoek-Oftedahl, W., \& Pearlman, D. N. (2003). Domestic violence incidents with children witnesses: Findings from Rhode Island surveillance data. Women's Health Issues, 13(2), 68-73.

Goleman, D. (1996). Emotional intelligence: Why it can matter more than $I Q$. Bloomsbury.

Her Majesty's Inspectorate of Constabulary. (2014). Everyone's business: Improving the police response to domestic abuse. HMIC.

Her Majesty's Inspectorate of Constabulary. (2015a). In harm's way: The role of the police in keeping children safe. HMIC.

Her Majesty's Inspectorate of Constabulary. (2015b). Increasingly everyone's business: A progress report on the police response to domestic abuse. HMIC.

Her Majesty's Inspectorate of Constabulary and Fire \& Rescue Services. (2019). The police response to domestic abuse. An update report. London: HMIC.

Hogan, F., \& O'Reilly, M. (2007). Listening to children: Children's stories of domestic violence. Dublin: Stationery Office.

Holt, S., Buckley, H., \& Whelan, S. (2008). The impact of exposure to domestic violence on children and young people: A review of the literature. Child Abuse \& Neglect, 32, 797-810.

Inzunza, M. (2015). Empathy from a police work perspective. Journal of Scandinavian Studies in Criminology and Crime Prevention, 16(1), 60-75. https://doi.org/10.1080/14043858.2014. 987518

Katz, E. (2016). Beyond the physical incident model: How children living with domestic violence are harmed by and resist regimes of coercive control. Child Abuse Review, 25(1), 46-59.

KIDSRIGHTS (2021). The Kids Rights Impact Report. Kids Rights Foundation, https://files.kidsrights.org/wp-content/ uploads/2021/06/03095317/KidsRights-Index-2021-Report. pdf. Accessed July 2021.

Kraska, P. B. (2007). Militarization and policing- Its relevance to 21st century policing. Policing: A Journal of Policy and Practice, 1(4), 501-513. https://doi.org/10.1093/police/pam065

Kugley, S., Wade, A., Thomas, T., Hahood, Q., Klintjorgensen, A., Hammerstrom, K., \& Sathe, N. (2011). Searching for studies: A guide for information retrieval for Campbell systematic reviews. The Campbell Collaboration.

Laming, H. (2003). The Victoria Climbié Inquiry: Report of an inquiry by Lord Laming. The Stationery Office.

Levendosky, A. A., Bogat, G. A., \& Huth-Bocks, A. C. (2011). The influence of domestic violence on the development of the attachment relationship between mother and young child. Psychoanalytic Psychology, 28(4), 512-527.

Lundy, L. (2007). 'Voice' is not enough: Conceptualising Article 12 of the United Nations Convention on the Rights of the Child. British Educational Research Journal, 33(6), 927-942.

Lundy, L., \& McEvoy, L. (2012). Children's rights and research processes: Assisting children to (in)formed views. Childhood, 19(1), 129-214.

McGee, C. (2000). Childhood experiences of domestic violence. Jessica Kingsley Publishers.

Millar, A., Devaney, J., \& Butler, M. (2018). Emotional intelligence: Challenging the perceptions and efficacy of 'soft skills' in policing incidents of domestic abuse involving children. Journal of Family Violence, 34, 577-588. https://doi.org/10.1007/ s10896-018-0018-9.

Mullender, A., Hague, G., Iman, U., Kelly, L., Malos, E., \& Regan, L. (2002). Children's perspectives on domestic violence. SAGE Publications.

Nordberg, A., Crawford, M. R., Praetorius, R. T., \& Hatcher, S. S. (2016). Exploring minority youths' police encounters: A qualitative interpretive meta-analysis. Child \& Adolescent Social Work Journal, 33, 137-149. https://doi.org/10.1007/ s10560-015-0415-3

Office for National Statistics (2018). Domestic Abuse in England and Wales: year ending March 2018. Avaiblable from https://www. ons.gov.uk/peoplepopulationandcommunity/crimeandjustice/ bulletins/domesticabuseinenglandandwales/yearendingmarch2018 [Accessed 4 June 2021]

Överlien, C., \& Hyden, M. (2009). Children's actions when experiencing domestic violence. Childhood, 16(4), 479-496.

Överlien, C., \& Aas, G. (2016). The police patrols and children experiencing domestic violence. Police Practice and Research, 17(5), 434-557.

Överlien, C., \& Holt. (2018). Including children and adolescents in domestic violence research. In S Holt, C Överlien., \& J Devaney (Eds), Responding to Domestic Violence : Emerging Challenges for Policy, Practice and Research in Europe. (pp. 97-112). London: Jessica Kingsley.

Powell, M. B., Skouteras, H., \& Murfett, R. (2008). Children's perceptions of the role of police: A qualitative study. International Journal of Police Science \& Management, 10(4), 464-473.

Pynoos, R. S., \& Nader, K. (1988). Children who witness the sexual assaults of their mothers. Journal of the American Academy of Child and Adolescent Psychiatry, 27(5), 567-572.

Richardson-Foster, H., Stanley, N., Miller, P., \& Thomson, G. (2012). Police intervention in domestic violence incidents where children are present: Police and children's perspectives. Policing and Society: An International Journal of Research and Policy., 22(2), 220-234.

Rodriguez, R., Macias, R., Perez-Garcia, R., Landeros, G., \& Martinez, A. (2018). Action research at the intersection of structural and family violence in an immigrant Latino community: A youth-led study. Journal of Family Violence, 33, 587-596. https://doi.org/ 10.1007/s10896-018-9990-3

Rowe, M. (2014). Introduction to policing (2nd ed.). SAGE Publications.

Russell, B., \& Sturgeon, J. A. (2019). Police evaluations of intimate partner violence in heterosexual and same-sex relationships: Do experience and training play a role? Journal of Police and Criminal Psychology, 34(1), 34-44.

Saxton, M. D., Jaffe, P. G., Dawson, M., Olszowy, L. \& Straatman, A. L. (2020). Barriers to police addressing risk to children exposed to domestic violence. Child Abuse \& Neglect, 106.

Sloan, J. J., \& Paoline, E. A. (2021). "They need more training!” A national level analysis of Police Academy basic training priorities. Police Quarterly, 0(0): 1-33

Stanley, N., Miller, P., Foster, H. R., \& Thomson, G. (2011). Children's experiences of domestic violence: Developing an integrated response from police and child protection services. Journal of Interpersonal Violence, 26(12), 2372-2391. https://doi.org/10. $1177 / 08862605103830300$

Stark, E. (2012). Looking beyond domestic violence: Policing coercive control. Journal of Crisis Negotiations, 12(2), 199-217.

Swerin, D. D., Bostaph, L. G., King, L. L., \& Gillespie, L. K. (2018). Police response to children present at domestic violence incidents. Child Maltreatment, 23(4), 417-425.

Tisdall, K., \& Punch, S. (2012). Not so 'new'? Looking critically at childhood studies. Children's Geographies, 10(3), 249-264.

United Nations Convention on the Rights of the Child (UNCRC). Adopted and open for signature, ratification and ascension by General Assembly Resolution 44/25 of 20th Nov 1989, entered into force 2nd Sept 1990, in accordance with Article 49. Available from: https://www.unicef.org.uk/wp-content/uploads/2010/ 05/UNCRC_united_nations_convention_on_the_rights_of_the_ child.pdf [Accessed 14 December 2018] 
United Nations International Children's Emergency Fund (UNICEF). (2017). A familiar face: Violence in the lives of children and adolescents. UNICEF.

Vermont Criminal Justice Training Council. (2007). Vermont's model protocol: Law enforcement response to children at the scene if a domestic violence incident. Vermont Criminal Justice Training Council: Vermont.

Walker, T., Shaw, J., Hamilton, L., Turpin, C., Reid, C., \& Abel, K. (2017). 'Coping with the job': Prison staff responding to self-harm in three English female prisons: A qualitative study. The Journal of Forensic Psychiatry and Psychology. https://doi.org/10.1080/ 14789949.2017.1331369

Publisher's Note Springer Nature remains neutral with regard to jurisdictional claims in published maps and institutional affiliations. 